\title{
JUZGADO DE LETRAS DE SAN MIGUEL, RIT O-458-2011. NO HUBO RELACIÓN LABORAL ENTRE UN DIRECTIVO Y UNA UNIVERSIDAD CON OCASIÓN DE SERVICIOS A HONORARIOS, AUNQUE PARALELAMENTE AQUEL HAYA PRESTADO SERVICIOS CON CONTRATO DE TRABAJO PARA LA MISMA UNIVERSIDAD. CONFIRMADA POR LA ILTMA. CORTE DE APELACIONES DE SAN MIGUEL N²6-2012 REF. LABORAL (EJECUTORIADA)
}

\author{
Claudio Palavecino Cáceres* \\ Universidad de Chile
}

\section{SÍNTESIS DEL CASO}

El caso que resuelve la sentencia que comento, lo plantea un profesional que demanda ante la jurisdicción laboral el reconocimiento de relación laboral con la universidad para la que prestó servicios como director de un programa especial de formación, contratado a honorarios, de manera paralela a las funciones que desempeñaba en esa misma universidad con contrato de trabajo. El demandante sostiene que la prestación de servicios, aunque formalmente se encuadró en un contrato de carácter civil, era, en la realidad de los hechos, de naturaleza laboral. En cambio, la universidad demandada insiste en que se trató de un contrato civil de arrendamiento de servicios profesionales. Por tanto, para resolver la controversia fue necesario determinar si tales servicios eran prestados por el actor bajo vínculo de subordinación y dependencia de la demandada en los términos del artículo $7^{\circ}$ del Código del Trabajo.

La sentenciadora concluyó que tales servicios no fueron prestados bajo subordinación y dependencia y rechazó la demanda con costas.

\section{FUNDAMENTOS DEL FALLO}

\subsection{AutONOMÍA DEL ACTOR EN DISEÑO Y GESTIÓN DEL PROGRAMA ESPECIAL DE FOR- MACIÓN}

El director del programa es quien se encargó de estructurar y fundamentar el proyecto, determinar las asignaturas y horarios, convocar a los docentes, programar los espacios físicos y hacerse cargo de los flujos económicos y viabilidad del proyecto.

Abogado, profesor de Derecho del Trabajo y la Seguridad Social de la Facultad de Derecho de la Universidad de Chile. 


\subsection{AutONOMÍA DEL ACTOR PARA LA CONTRATACIÓN DE PERSONAL PARA LA EJECU- CIÓN DEL PROGRAMA ESPECIAL DE FORMACIÓN}

Los directores de estos programas especiales desarrollaban sus funciones con gran independencia y autonomía pudiendo incluso autocontratarse para labores de docencia en los mismos o inclusive contratar a parientes, como en el caso del demandante.

\subsection{EMISIÓN DE BOLETAS DE HONORARIOS POR EL ACTOR}

Mensualmente el actor gestionaba el pago de sus honorarios presentando el respectivo formulario y remitiendo la boleta correspondiente, gestión esta que sin duda no se encuadra dentro del marco de una relación laboral.

\subsection{EL ACTOR NO PRESTABA SERVICIOS DE MANERA EXCLUSIVA PARA LA UNIVERSIDAD DEMANDADA}

Durante el lapso en que se desempeñó como director del programa especial, el demandante también prestó servicios para otras instituciones, puesto que las boletas de honorarios incorporadas por el propio actor no son correlativas en su numeración e incluso en algunos meses existen varias boletas de por medio, lo que sin lugar a dudas da cuenta de otras prestaciones de servicios por parte del demandante.

\subsection{TAMBIÉN EL PRESTADOR DE SERVICIOS INDEPENDIENTES ESTÁ SUJETO A CIERTAS DIRECTRICES \\ Nada obsta que en una prestación de servicios a honorarios se den directrices por} parte de quien los contrate, más aún cuando, como en la especie, se trata del director de un programa de formación que se encuentra inserto dentro del plan educacional de una universidad, resultando absolutamente lógico que se exija una planificación y una rendición de cuenta de los recursos que se administran en tal calidad.

\subsection{EL ACTOR NO ESTABA EN UNA POSICIÓN DE DEBILIDAD FRENTE A SU EMPLEADOR}

No se trata en la especie de un trabajador que se encuentre en una situación de desventaja o desigualdad frente a su empleador, a quien pueda imponérsele condiciones no queridas, sino de un profesional calificado, quien dada su profesión de administrador público y habiéndose desempeñado por largo tiempo como director de la carrera de auditoría, tenía pleno y cabal conocimiento de las diferencias e implicancias jurídicas de un vínculo de carácter laboral y de una prestación de servicios a honorarios, como la que en definitiva lo vinculó con la demandada.

\subsection{LA PRETENSIÓN DEL ACTOR CONTRADICE SU CONDUCTA PRECEDENTE (TEORÍA DE LOS ACTOS PROPIOS) \\ El demandante es un profesional administrador público que ha desarrollado docencia} en diversas instituciones y que durante un extenso periodo de tiempo implementó y desarrolló un programa, emitiendo por ello boletas de honorarios, efectuándosele las respectivas retenciones de impuestos, por las que percibiera las correspondientes devoluciones, tal como consta de las declaraciones de renta por este exhibidas y que teniendo pleno y cabal cono- 
cimiento de sus derechos, no formuló denuncia alguna ante las autoridades pertinentes respecto de la naturaleza de los servicios prestados, ni de las materias demandadas en la presente causa, habiendo incluso reconocido al absolver posiciones que nunca pidió formalmente que se le escriturara un contrato de trabajo, manteniéndose en dicha situación por más de 7 años y reclamando de ello solo una vez que sus servicios concluyeron, lo que no solo vulnera el principio de buena fe contractual, sino que contraría la conducta mantenida por el propio actor durante tan extenso periodo de tiempo.

\section{COMENTARIO}

El arrendamiento de servicios inmateriales es aquel en que predomina la inteligencia sobre el esfuerzo puramente manual (art. 2006 CC). El CC distingue tres clases de arrendamiento de esta especie: servicios aislados en que predomina la inteligencia sobre la mano de obra (v. gr. una composición literaria o musical, o la corrección tipográfica de un impreso); servicios que consisten en una larga serie de actos (como los de los escritores asalariados para la prensa, secretarios de personas privadas, preceptores, ayas, histriones y cantores) y los servicios profesionales (en palabras de Bello "los servicios de profesiones y carreras que suponen largos estudios, o a las que está unida la facultad de representar y obligar a otra persona respecto de terceros").

El contrato de arrendamiento de servicios fue el precedente histórico del contrato de trabajo que vino a sustituirlo, si bien no por completo, por lo que actualmente tiene una vigencia puramente residual, es decir, solo será la fuente de una prestación de servicios retribuida cuando no existe relación de subordinación o dependencia entre las partes que la acuerdan, esto es, cuando se trata de servicios independiente o autónomos.

En efecto, el inciso primero del art. $8^{\circ} \mathrm{CT}$ establece que toda prestación de servicios en los términos señalados en el artículo anterior $\left(7^{\circ} \mathrm{CT}\right)$-esto es, personal, remunerada y bajo dependencia y subordinación del empleador- hace presumir la existencia de un contrato de trabajo. Es una presunción simplemente legal -iuris tantum-, la cual, como se sabe, admite prueba en contrario. Al efecto señala el art. $47 \mathrm{CC}$ que "se permitirá probar la no existencia del hecho que legalmente se presume, aunque sean ciertos los antecedentes o circunstancias de que lo infiere la ley (...). Sin embargo, en la práctica, probada que sea la prestación de servicios personales remunerados bajo subordinación y dependencia, la presunción del art. $8^{\circ} \mathrm{CT}$ viene siendo aplicada por los tribunales del trabajo como una presunción iure et de iure, aun cuando la intención común de las partes hubiere sido celebrar un contrato distinto del contrato de trabajo, puesto que para estos efectos la expresión del consentimiento carece de toda relevancia para la calificación jurídica de la situación controvertida. Tal es lo que ocurre, frecuentemente, con la celebración del llamado "contrato de honorarios" en que las partes no han querido celebrar un contrato de trabajo, sino uno de naturaleza civil (técnicamente arrendamiento de servicios).

De ahí que los fundamentos centrales del fallo (1 a 5) se centran en dar razón de por qué la sentenciadora estima que no se configura el vínculo de subordinación. En este grupo de argumentos es importante destacar que la sentenciadora comprende perfectamente que las modalidades arrendaticias del CC no son ajenas a cierto grado de control en la ejecución 
del servicio por la parte que lo encargó y que, por tanto, la constatación de la subordinación es una cuestión de intensidades. En efecto, si la subordinación la concebimos en términos literales (sujeción a la orden, mando o dominio de alguien), pierde toda cualidad tipificante. ¿No está acaso el mandatario subordinado a las órdenes del mandante o el artífice, a las directrices del que le encarga la obra? Como dice Meda, la subordinación "significa que el asalariado se sitúa bajo la dirección y autoridad del que lo contrata; éste dará las órdenes relativas a la ejecución del trabajo, controlará la realización y verificará los resultados. Aunque la subordinación no es personal sino jurídica, es, no obstante, total: el asalariado hará lo que se le pida, de la manera que se le indique y en el contexto de una organización que le vendrá impuesta; y lo realizará, además, sin conocer la finalidad de su acción, puesto que no participa en la toma de decisiones de la empresa $(\ldots)^{1}$.

Con todo, la parte más interesante del fallo viene dada por los argumentos 6 y 7 , ofrecidos "a mayor abundamiento".

Es verdad que la invocación del principio de primacía de la realidad ha permitido en muchas ocasiones a los jueces del trabajo una revisión del elemento volitivo del contrato, más allá del enfoque tradicional de la "fuerza" propia del Derecho civil, y de ese modo sortear el querer declarado por las partes celebrantes de un contrato civil, cuando incluso, conociendo el trabajador, la naturaleza jurídica material del contrato que celebra, ha consentido en conferirle un encuadramiento jurídico distinto.

Pero esa revisión de la voluntad declarada solo podría justificarse cuando la realidad de las circunstancias materiales o morales que rodean al trabajador permiten al juez formarse la convicción de una afectación grave de su libre arbitrio. En este orden de ideas, salta a la vista la importancia y efectos del art. $8^{\circ}$ inciso primero del CT, toda vez que se constituye en una excepción al art. $1560 \mathrm{CC}^{2}$, el cual obliga al intérprete estarse en una relación entre privados a la intención que declaran las partes, puesto que las partes al estar en una igual libertad para contratar, declararán, si no están en un error, estar celebrando el contrato que su libre arbitrio quiere. En otras palabras, el art. 1560 CC nos dice que la intención que declaran las partes es efectivamente lo que quieren y a la cual debemos estarnos para no violar el principio de la autonomía de la voluntad, salvo que exista un vicio de la voluntad (error, fuerza o dolo) o, ahora ya desde las normas propias del Derecho del trabajo, una voluntad fuertemente constreñida por las circunstancias materiales o morales. De esta manera, se desprende razonablemente que el querer declarado por el prestador de servicios personales no forma necesariamente expectativas confiables en su contraparte, en tanto sabe este último que lo declarado se encuentra afectado por las circunstancias materiales donde se desenvuelve la voluntad. ${ }^{3} \mathrm{Y}$ esta debilidad material o moral del trabajador no es un juicio a priori que

\footnotetext{
MedA, Dominique. El Trabajo. Un valor en peligro de extinción. Barcelona, España: Gedisa, 1998, pp. 118-119.

2 Para Barcia, el artículo 1560 establece una restricción consistente en impedir que el juez pueda interpretar contra la voluntad declarada y clara de las partes. BARCIA, Rodrigo. Lecciones de Derecho Civil Chileno. Tomo II. Santiago, Chile: Editorial Jurídica de Chile, p. 23. En igual sentido, López Santa María sostiene que el CC limita la interpretación, contra lo expresamente declarado, a la voluntad claramente conocida de los contratantes. LÓPEZ, Jorge. Los contratos. Parte General. Santiago, Chile: Editorial Jurídica de Chile, 1986, p. 312.

3 Así en el interesante trabajo de HORMAZÁBAL, Mauricio. "El contrato formalmente civil de prestación de servicios como supuesto de aplicación del orden público laboral. Certeza y justicia en la excepción a la igualdad ante la ley”, en: Revista Chilena de Derecho del trabajo y de la seguridad social, volumen 3, No 5, Santiago, Chile, pp. 79-91.
} 
ya contenga la norma, sino que debe ser constatada en concreto por el juez de la causa. En el caso que resuelve, la sentenciadora comprobó que no se trataba de un obrero sin cualificación, ignorante de sus derechos o temeroso de ejercerlos, y apremiado por circunstancias vitales a incrementar el saldo líquido de su remuneración, aun a costa de su futura pensión, sino de un hombre educado, un profesional cualificado y de ingresos relativamente altos que no ha obrado constreñido por las circunstancias materiales o morales sino con voluntad plena y libre.

Finalmente, destaco la aplicación de la teoría de los actos propios, conforme con la cual a nadie es lícito hacer valer un derecho en contradicción con su anterior conducta y que se plasma en la máxima venire contra factum propium non valet ${ }^{4}$. Si bien se han alzado voces críticas contra la aplicación de esta teoría en causas laborales ${ }^{5}$, lo cierto es que ella tiene plena cabida en el ámbito laboral, pues como reiteradamente lo ha decidido la Excma. Corte Suprema de Justicia, la legislación laboral no puede considerarse en forma aislada del ordenamiento jurídico general, que regula las vinculaciones que generan los sujetos del derecho y que, en el caso, se ha traducido en la aceptación por parte del demandante de la existencia de una relación de naturaleza civil con sus respectivas consecuencias, prolongadamente en el tiempo, sin haber formulado reclamo alguno en tal sentido. Los tribunales venían aplicando desde antaño, aunque de manera heurística, esta teoría a propósito del "tácito perdón de la causal de despido" cuando el empleador, que primero pasaba por alto una conducta del trabajador acreedora del despido disciplinario y generaba en este la legítima expectativa del perdón, pretendía luego, tardíamente, hacerla valer en su contra. Entonces, los ahora críticos, nada dijeron.

\footnotetext{
4 Vid. EKDAHL, María Fernanda. La doctrina de los actos propios. El deber jurídico de no contariar conductas propias pasadas. Santiago, Chile: Editorial Jurídica de Chile, 1989, p. 25.

5 Por todos, CAAMAÑo, Eduardo. "Análisis crítico sobre la aplicación de la doctrina de los actos propios en materia laboral", en: Revista de Derecho de la Pontificia Universidad Católica de Valparaíso, N³2, 2009, pp. 261-280.
} 